\title{
Interventional catheterization in pediatric catheterization laboratories for congenital and structural heart defects during 2009-2018 in Poland. Report of the National Consultant of Pediatric Cardiology
}

\author{
Jacek Białkowski, Małgorzata Szkutnik, Agnieszka Powałka \\ Congenital Heart Diseases and Pediatric Cardiology Department, Medical University of Silesia, Silesian Center for Heart Diseases, Zabrze, \\ Poland
}

Adv Interv Cardiol 2019; 15, 3 (57): 374-376 DOI: https://doi.org/10.5114/aic.2019.87899

Over the last 20 years interventional catheterization has become the procedure of choice for the treatment of several congenital and structural heart defects (CHD). Published data of the activities of pediatric catheterization laboratories (cath labs) in Poland are limited [1-4].

A National Consultant of Pediatric Cardiology (JB) for several years has collected data from all pediatric cath labs in Poland regarding their activities. They included details of interventional procedures performed in CHD in children and adults.

There are 10 pediatric cath-lab centers in Poland (all with a department of pediatric cardiac surgery) - two in Warsaw (Instytut Pomnik Centrum Zdrowia Dziecka - CZD and Warsaw Medical Iniversity - WUM), two in Gdansk (Uniwersyteckie Centrum Kliniczne - UCK and PCT Hospital), and a single one in: Lodz - Instytut Pomnik Centrum Zdrowia Matki Polki (CZMP); Poznan - Uniwersytet Medyczny (UM); Katowice - Górnośląskie Centrum Zdrowia Dziecka (GCZD); Wroclaw - Wojewódzki Szpital Specjalistyczny (WSS); Krakow - Uniwersytecki Szpital Dziecięcy (USD) and Zabrze - Śląskie Centrum Chorób Serca (SCCS). All of them reported their activities yearly from 2009 to 2018 except 2 centers; one in Katowice and another one in Gdansk (PTC) which started working in 2011. There are currently 14 operators of pediatric cath labs in Poland most of them more than 50 years old (yo).

There were 17054 interventional catheterizations in CHD reported in the period 2009-2018 including 2080 (12.2\%) procedures conducted in adult patients ( $>18$ yo) - Table I. The latter procedures were performed generally in 4 cath labs: SCCS Zabrze, UCK Gdansk, WSS Wroclaw and CZMP Lodz. The number of CHD surgical operations (in children and adults) were collected from 10 units mentioned above (having specific Pediatric cath labs) in the Polish Cardiac Surgery Registry (KROK Report - Rejestr Operacji Kardiochirurgicznych w Polsce). They reported $93.5 \%$ of all surgical procedures performed in $\mathrm{CHD}$ in Poland.

The numbers of interventional procedures vs. surgical operations in CHD during the period 2009-2018 are presented in Figure $1 \mathrm{~A}$. It is clear that the number of interventional catheterizations has consistently increased during that time whereas surgical procedures have remained constant. It is important to state that the number of surgical and interventional procedures in the year 2018 were similar (2293 vs. 2271). Obviously the surgical procedures were different in distinct CHD than catheter interventions, but it was not analyzed in this study.

Activities of particular Pediatric cath labs in Poland from 2009 to 2018 are presented in Figure 1 B. Four of them (CZD Warsaw, CZMP Lodz, USD Krakow, SCCS Zabrze) in the year 2018 performed more than 270 procedures. The remaining 6 cath labs performed more than 123 procedures in the year 2018. Generally all Pediatric cath labs continuously increased their activities.

Table I compares different types of interventional catheterizations performed in pediatric cath labs in Poland from 2009 to 2018 in child and adult patients. The most frequent procedures in children were patent ductus arteriosus (PDA) and atrial septal defect type II (ASD) percutaneous closure (35\%). Different balloon angioplasty (BAP) and valvuloplasty (pulmonary - BPV or aortic - BAV) - constituted $23 \%$ of all pediatric procedures. BAP was conducted mostly in pulmonary arteries

\section{Corresponding author:}

Prof. Jacek Białkowski MD, PhD, Congenital Heart Diseases and Pediatric Cardiology Department, Medical University of Silesia, Silesian Center for Heart Diseases, 9 M. Curie-Skłodowskiej St, 41-800 Zabrze, Poland, phone/fax: +48 3227134 01, e-mail: jabi_med@poczta.onet.pl Received: 2.07.2019, accepted: 13.07.2019. 


\section{A}

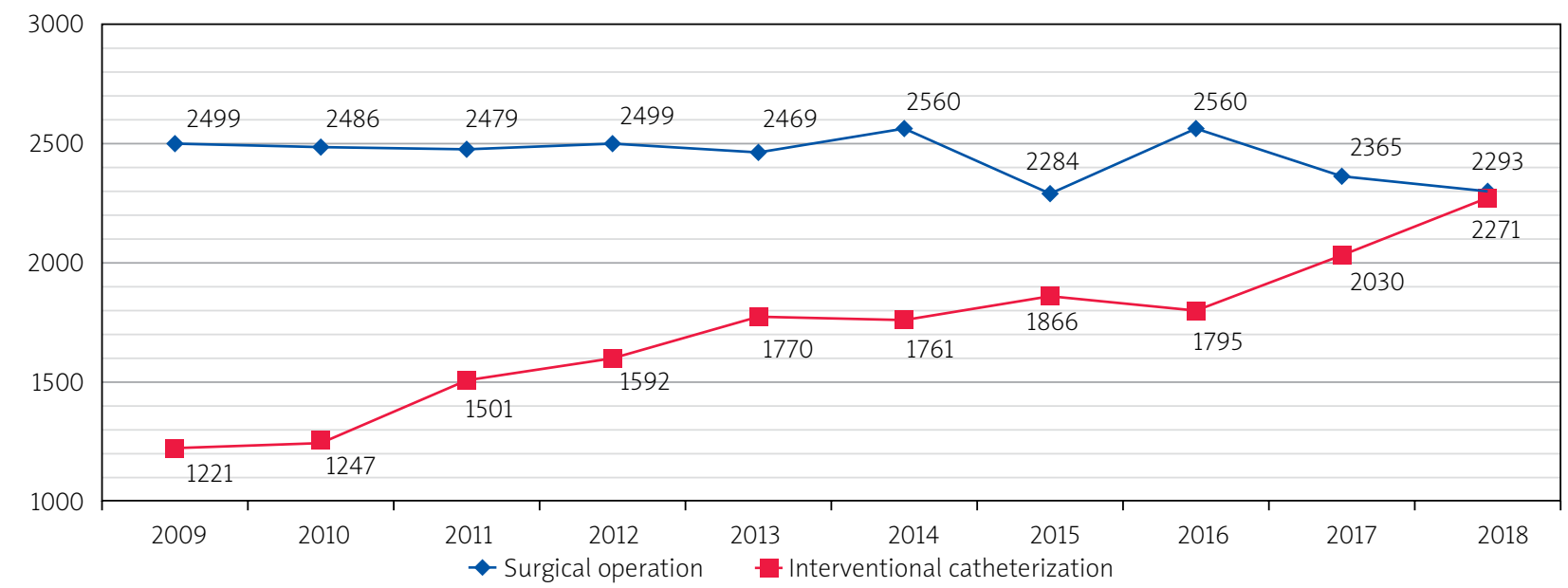

B

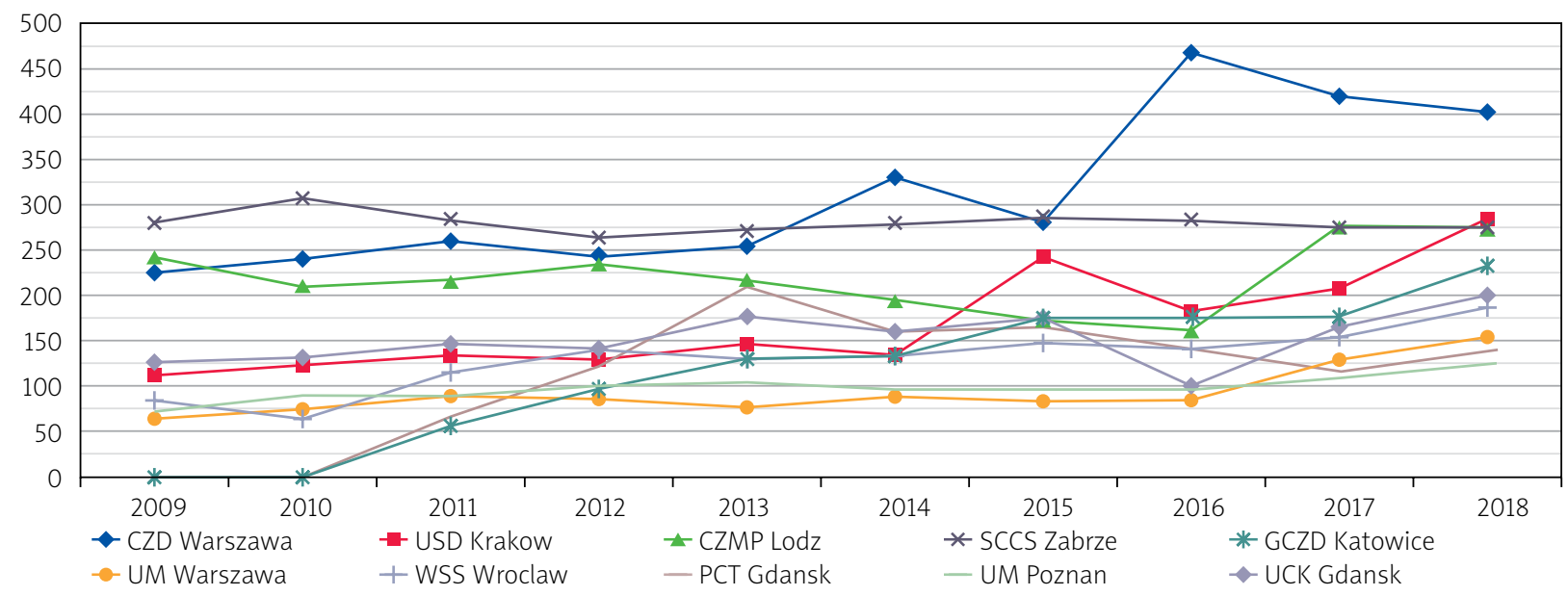

Figure 1. Interventional catheterization in pediatric cath labs in congenoital heart defects in Poland performed in the years 2009-2018. A - interventional catheterization vs. surgical operations. B - Interventional procedures in particular pediatric cath lab

(PA) or coarctation/recoarctation of the aorta (COA) and were performed at a similar rate in children. BPV was performed more often than BAV. Another frequent procedure in children was stent implantations, mainly in PA and COA (9.2\% of all interventions). The absolute number of Rashkind procedures remained stable during the analyzed decade. Patent foramen ovale (PFO) percutaneous closure was performed in only 36 children during the period of the study, reflecting the low necessity of such procedures in pediatric populations [5].

In adult patients ASD and PFO closures were the most predominant procedures (about $70 \%$ of all) - Table I. There is an important discrepancy between our findings and the AISN PTK register on ASD percutaneous closure in Poland. For example in 2017 [4] they reported 229 of such patients (not specified whether children or adults) in whom ASD was closed. In our own registry from only Pediatric cardiology cath labs there were 349 such patients (56 adults) in 2017 and 374 (76 adults) in 2018.
It is not clear if the AISN PTK registry includes pediatric cath-lab data.

In Table I "Other interventions" represented a large number of the performed procedures. They included several, different interventions: percutaneous perimembranous and muscular ventricular septal defect (VSD) closure (179 patients - 36 adults), foreign body removal from circulatory system (92 patients -7 adults) or stent implantation in PDA (neonates), percutaneous closure of postinfarction VSD (adults), different hybrid procedures, etc. Pulmonary artery valve transcatheter implantation (PAVTI) was performed in 80 patients ( 23 adults). It is important to mention that our data do not include "adult" interventional centers such as the National Institute of Cardiology in Warsaw, where the majority of PAVTI were performed.

In conclusion, there was a constant significant increase in the total number of interventional procedures seen in pediatric cath labs in Poland in children and sta- 


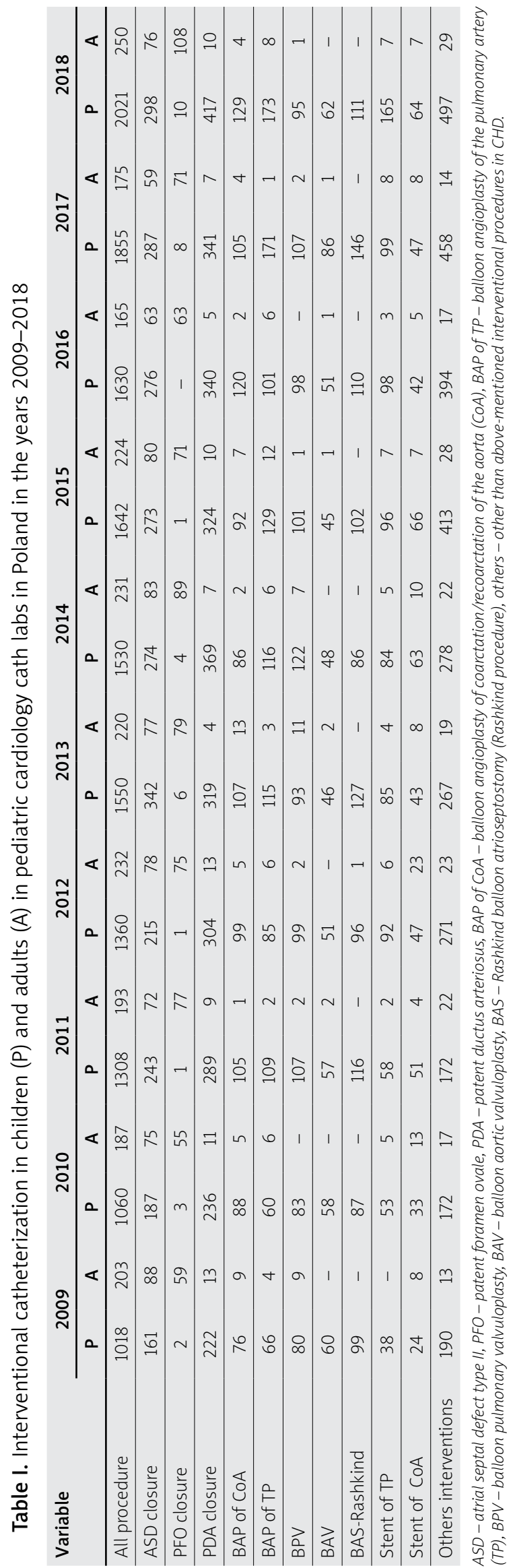

ble numbers in adults during the last decade. The small number and older age of the interventional pediatric cardiologist in Poland are worrisome. We hope that the new European Union and Polish Ministry of Health project "Power-KID" will help to stimulate and to activate new, younger pediatric cardiologists to become interventional operators working in pediatric cath labs. Adult interventions in CHD performed by pediatric cardiologists are a good option, but depend on the organizing structure of the hospital.

A limitation of this study is the voluntary register of pediatric cath labs activities. Unfortunately, mortality and serious complications of these procedures were not analyzed, but it is a well-known fact that they are anecdotal and very rare.

\section{Acknowledgments}

We would like to thank Dr Yves Mutabandama for linguistic correction of this article.

\section{Conflict of interest}

The authors declare no conflict of interest.

\section{References}

1. Kleczyński P, Siudak Z, Dziewierz A, et al. The network of invasive cardiology facilities in Poland in 2016 (data from ORPKI Polish National Registry). Kardiol Pol 2018; 76: 805-7.

2. Legutko J, Siudak Z, Parma R, et al. Poland: coronary and structural heart interventions from 2010 to 2015. Eurointervention 2017; 13: Z51-4.

3. Ochała A, Siudak Z, Legutko J, et al. Percutaneous interventions in cardiology in Poland in the year 2014. Summary report of the Association of Cardiovascular Interventions of the Polish Cardiac Society ASIN PTK. Postep Kardiol Inter 2015; 11: 177-81.

4. Dudek D, Siudak Z, Legutko J, et al. Percutaneous interventions in cardiology in Poland in the year 2017. Summary report of the Association of Cardiovascular Interventions of the Polish Cardiac Society AISN PTK and Jagiellonian University Medical College. Adv Interv Cardiol 2018; 14: 422-4.

5. Wawrzyńczyk M, Gałeczka M, Karwot B, et al. Efficiency of transcatheter patent ovale closure in children after paradoxical embolisation events. Kardiol Pol 2016; 74: 385-9. 